\title{
Sustaining thermal power plant production in low water supply regions using cooling towers
}

\author{
H. H. Al-Kayiem ${ }^{1}$ \& M. A. W. Theeb ${ }^{2}$ \\ ${ }^{1}$ Mechanical Engineering Department, \\ Universiti Teknologi PETRONAS, Malaysia \\ ${ }^{2}$ Mechanical Engineering Department, Al-Mustansirya University, Iraq
}

\begin{abstract}
Climate and geographical changes are among many other reasons causing water depletion. This may cause reduction in water resourcing from rivers and lakes to cool existing or planed thermal power plants. The present paper presents an alternative way to treat the water shortage problem by using cooling towers. The paper presents the design and analysis of a closed cooling system for a $200 \mathrm{MW}$ thermal power plant with a partial addition from the natural resources of $10 \%$, $20 \%, 30 \%$, and $40 \%$ mixing ratios. The hydrothermal process of the condenser and the cooling tower were modelled and solved computationally using weather data of Baghdad. Two types of cooling towers have been investigated using different types of locally made fills. The procedure has been validated using in-service power plant data. An interesting finding from the numerical analyses of the cooling tower indicated that there is an optimum size for the cooling tower for best performance. It is recommended to design the cooling system with a $15 \%$ to $25 \%$ mixing ratio. Cross flow cooling tower was able to produce cooling water with $1^{\circ} \mathrm{C}$ compared to the cross flow cooling tower.
\end{abstract}

Keywords: cooling towers, thermal power plant, energy technology.

\section{Introduction}

Rankine cycle, shown in Fig. 1, is the ideal cycle for steam power plants. The cycle is composed of four internally reversibly processes: Constant pressure heat addition in the boiler, isentropic expansion in the turbine, constant pressure 
heat rejection in the condenser, and isentropic compression in the pump. Modifications to the cycle have been made in order to increase the efficiency of the cycle. Among them is by decreasing the average temperature at which heat is rejected from the working fluid. This process takes place during the condensation of the steam in the condenser making use of the negative pressure inside the condenser.

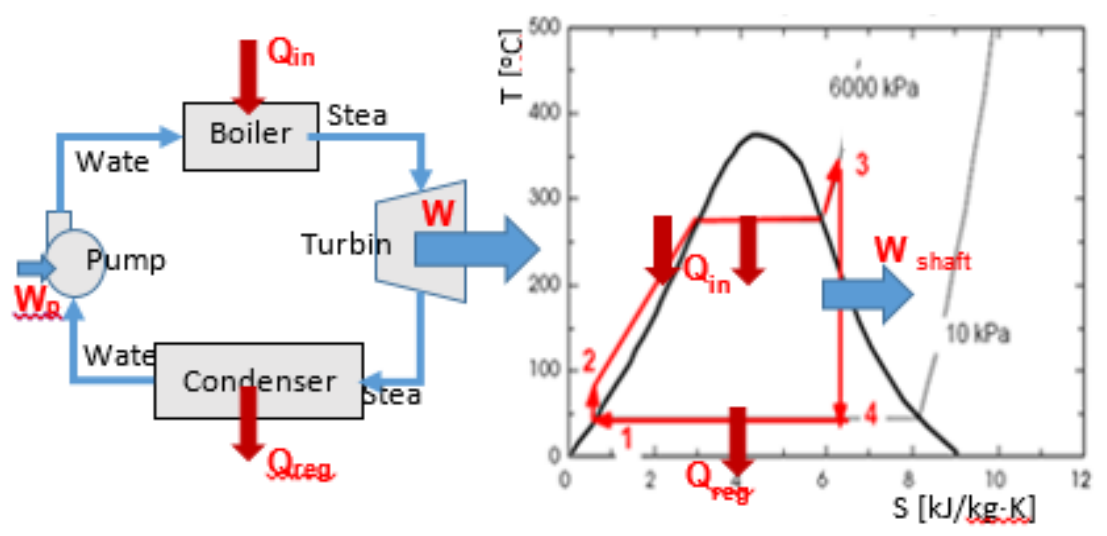

(a)

(b)

Figure 1: (a) Basic steam power cycle, (b) T-s diagram of Rankine cycle.

For the purpose of heat transfer from the core, the water is circulated continuously in a closed loop steam cycle and hardly any is lost. It is turned to steam by the primary heat source in order to drive the turbine to do work making electricity, and it is then condensed and retuned under pressure to the heat source in a closed system. A very small amount of make-up water is required in any such system. The water needs to be clean and fairly pure. This function is much the same whether the power plant is nuclear, coal-fired, or conventionally gas-fired. Any steam cycle power plant functions in this way. At least $90 \%$ of the non-hydro electricity in every country is produced thus [1].

However, to condensate the steam to return to the boiler in a liquid phase, the condensation process involves heat rejection from the working fluid. The heat rejection process requires circulating cold water to the condenser. The circulatingwater system supplies water to the condenser and thus acts as the automobile by which heat is rejected from the steam cycle to the environment. Circulating-water systems are broadly classified as, Once-through, Closed-loop and Combination system (El-Wakil [2], Al-Kayiem and Theeb [3]).

Water depletion or less resourcing, in many regions in the earth is realized as main problem for human needs and for industrial application, like cooling of thermal power plants. An example of that is the large shortage of water resources in Iraq which is caused due to the dams' establishment by the Turkish side on Tigris \& Euphrates Rivers. Such situation necessitates the need for thermal power 
plants that require less water. Cooling Tower (CT) helps by reusing the cooling water, making power plants economical and more environmentally friendly.

The objective of this paper is to present the outlines of the design and analysis of CT to compensate for the lack of water supply to cool the condenser of a 200MW steam power plant. This plant is the "First National Thermal Power Station" located in south of Baghdad. The circulating cooling system was proposed to be supplied by water from Alyosofiyah River. The close CCS was decided after the neighboring countries, Syria and Turkey, established many dams on the Euphrates River which caused huge shortage in the water resources in Iraq.

\section{Plant cooling system}

Usually, the cold circulating water is supplied from continuous water source, e.g. a lake, river, or sea water. Water receives the rejected heat and return back to the source. This type of cold water supply is cold "Open Cooling System", (OCS). In cases of shortage of the cold water supply for any reason, the designers adopt closed loop or what is called "Closed Cooling System" (CCS), where the cooling water is circulated in a closed loop consisting of CT unit to reject the heat from the condenser water to the open atmosphere. In some cases, some percent of the cooling water is added from the available natural water resources to the closed system. This is called combined cooling system. This will reduce the size of the $\mathrm{CT}$. The percentage of the added water from the nearby source is called Coolant Mixing Ratio (CMR). When the CMR is zero, it is completely closed system. When the CMR is $100 \%$, it is OCS. Some designers prefer to add the cold water to the warm line from the condenser to the $\mathrm{CT}$, while some prefer to add the cooling water to the cold water passing from the CT to the condenser. The two methods are shown in Fig. 2.

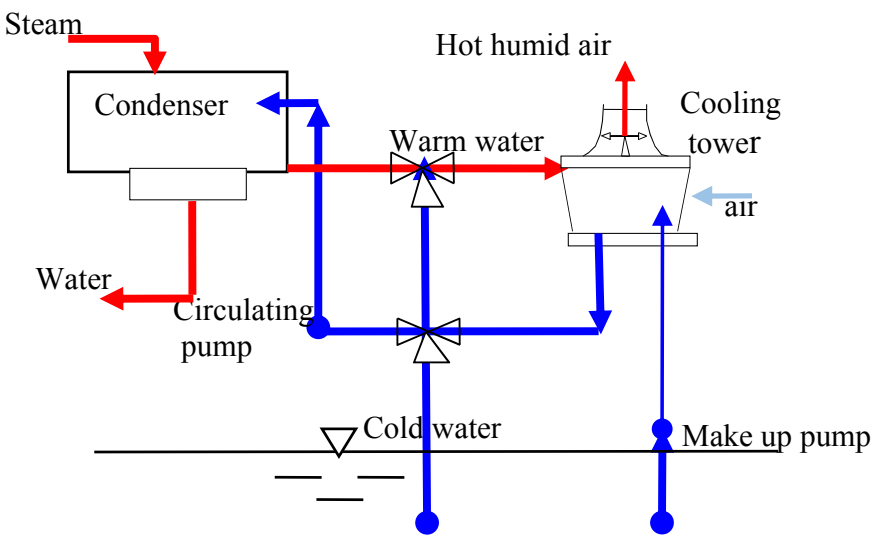

Figure 2: Combined cooling system. 


\section{Hydrothermal modeling of the condenser}

Steam leaving from the turbine is cooled and condensate in vacuum environment inside the condenser and accumulated in the sump downside of the condenser to recirculated, by pumping, to the boiler unit. In the condenser the latent heat of the turbine exhaust steam is transferred to cooling water and eventually dissipated to the atmosphere. The frequently used type of condenser in the thermal power plants is the water-cooled surface condenser, in which the circulating water passes through the condenser tubes and picks up the latent heat from steam condensing on the outer surface of the tube. The steam temperature, $T_{s}$ is the saturation temperature at the condenser pressure. The difference between the steam temperature and water inlet temperature, $T_{w l}$ is defined as the initial temperature difference (ITD). The difference between the steam temperature and the water exit temperature, $T_{w 2}$ is known as Terminal Temperature Difference (TTD). The mean temperature difference across the condenser is obtained from the application of the well-known heat exchanger theory available in numerous heat transfer references.

$$
\begin{gathered}
q_{r e j}=U A \Delta T_{m} \\
\Delta T_{m}=\frac{(I T D)-(T T D)}{\ln \left(\frac{I T D}{T T D}\right)}
\end{gathered}
$$

where, $q_{r e j}$ is the rejected heat from condenser (Watt) and $\Delta T_{m}$ is frequently referred to as Logarithmic Mean Temperature Difference (LMTD).

Since the operating temperatures of the steam and the cooling water are not fixed at a certain design point, consequently, the condenser evaluation must be based on the design as well as off-design performances. In other words, the ITD and TTD are not constants and it is preferable to write eq. 2 as (Li and Priddey [4])

$$
q_{r e j}=U A \frac{\left(T_{s}-T_{1}\right)-\left(T_{s}-T_{2}\right)}{\ln \left(\frac{T_{s}-T_{1}}{T_{s}-T_{2}}\right)}
$$

where, on the water side,

$$
q_{r e j}=m_{w} C_{p w}^{\cdot}\left(T_{2}-T_{1}\right)
$$

Eqns 2, 3 and 4 may be manipulated; leading to:

$$
T_{s}=\frac{\frac{q}{\dot{m}_{w} C_{p w}}+T_{1}\left(1-\exp \left(-\frac{U A}{\dot{m}_{w} C_{p w}}\right)\right)}{1-\exp \left(-\frac{U A}{\dot{m}_{w} C_{p w}}\right)}
$$


The equation is applicable for new condenser design and tubes sizing in terms of number and diameter. It is valid in the early stages of the installation of the condenser. After a short while of operation, the nature of the tube internal and external surfaces are changing and the prediction of the heat transfer mechanism become rather complex. Further empirical correlations may be adopted for proper prediction of the condenser design (El-Wakil [2]).

\section{Modeling of the cooling tower}

The CT is a thermal device which transfers thermal energy from warm water to air stream. Two types of CT may use in the power plants; either cross flow type or counter flow type. In the present work, both have been analyzed and the selection was based on the results obtained and the availability of the construction materials Consider a $\mathrm{CT}$ having one square meter of plan area, cooling volume $\mathrm{V}$, containing $a \mathrm{~m}^{2}$ of extended water surface per $\mathrm{m}^{3}$, water mass flow rate $m_{w}$, and air mass flow rate $m_{a}$, both in $\mathrm{kg} / \mathrm{s}$. The mechanism of mass and energy transfer is modeled in presence of three regions, the bulk water, the bulk air and intermediate phase between them. The intermediate zone is similar to a film of saturated air. The bulk water at temperature, $t$ is surrounded by the bulk air at dry-bulb temperature $t_{a}$, having enthalpy $h_{a}$ and humidity ratio $W_{a}$. The interface is assumed to be a film of saturated air having an intermediate temperature, $\mathrm{t}_{\mathrm{w}}$ and humidity ratio, $W_{w}$.

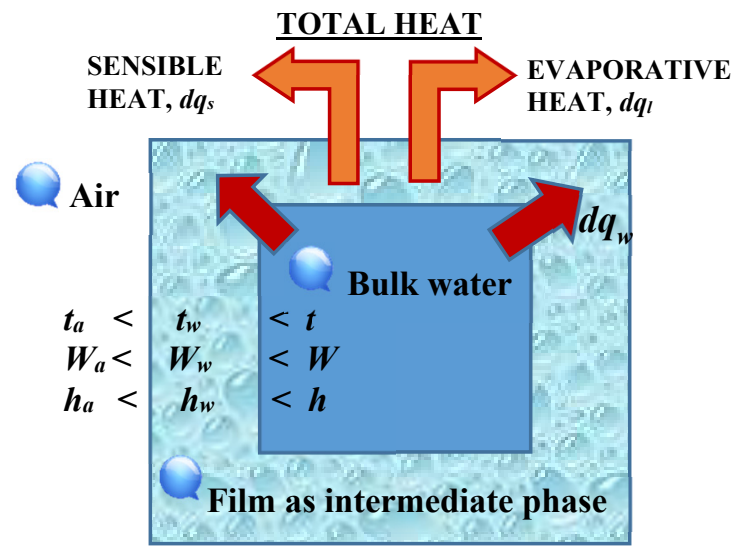

Figure 3: Heat and mass balance modeling in an element in the CT.

The heat transfer from the water to the interface is:

$$
d q_{w}=m_{w} C_{p w} d t \dot{=} k_{l} a d V\left(t-t_{w}\right)
$$

where, $q_{w}$ is rate of heat transfer, from bulk water to interface, (W) and $k_{l}$ is convective heat transfer coefficient, bulk water to interface, $\left(\mathrm{W} / \mathrm{m}^{2} \cdot \mathrm{K}\right)$. 
The sensible heat transfer from the interface to the air stream is:

$$
d q_{s}=h_{\text {sen }} a \dot{d} V C_{p w}\left(t_{w}-t_{a}\right)
$$

where, $h_{\text {sen }}$ is overall sensible heat transfer coefficient between interface and main air stream, $\left(\mathrm{W} / \mathrm{m}^{2} \cdot \mathrm{K}\right)$.

The diffusion of water vapor film to air stream is:

$$
d m_{w t}=k \backslash a \dot{d} V\left(W-W_{a}\right)
$$

where, $m_{w t}$ is the mass transfer rate at interface to air stream, $(\mathrm{kg} / \mathrm{s})$ and $k^{\dagger}$ is the mass transfer coefficient from interface to main air stream, $\left(\mathrm{kg} / \mathrm{s} . \mathrm{m}^{2}\right)$.

The latent heat transfer rate is [5]:

$$
\boldsymbol{r} d m_{w t}=d q_{l}=\boldsymbol{r} k \backslash a \dot{d} V\left(W-W_{a}\right)
$$

where, $\boldsymbol{r}$ is the latent heat of evaporation constant.

The heat exchangers are usually characterized by the Number of Transfer Unit, (NTU). Since the CT has similar hydrothermal operation principles as of the HEX, then it is possible to characterize the CT performance using the NTU method.

\subsection{Counter flow CT}

Fig. 6 shows a differential volume in counter flow CT with $m_{w} \mathrm{~kg} / \mathrm{s}$ of water drop from the top and $m_{a} \mathrm{~kg} / \mathrm{s}$ of air entering from the bottom with properties at inlets and outlets shown in Fig. 4. A small quantity of water is evaporated.

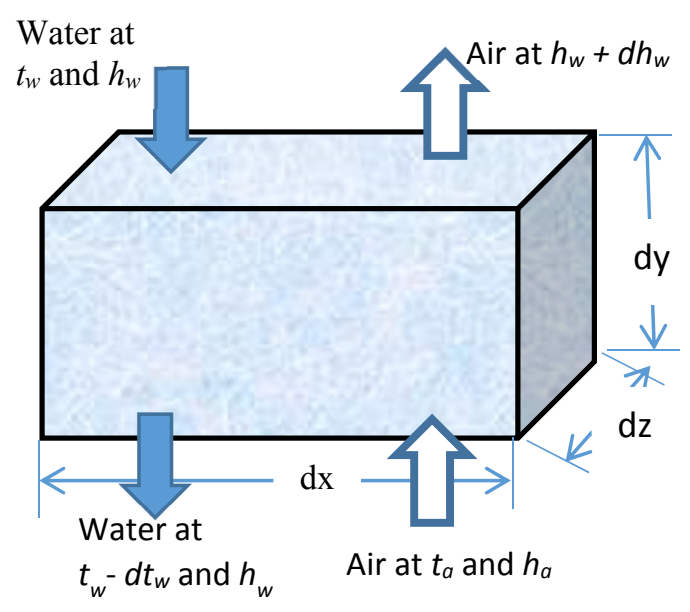

Figure 4: Differential control volumes in counter flow CT. 
The total area of wetted surface, $d A$ includes the surface area of the drops of water as well as the wetted slats or other fill material. By heat and mass balance based on the balances of Fig. 3 and adopting Lewis approximation at the interface, the following considered holds [5]:

$$
k \backslash \frac{c_{p}}{h}=1
$$

Integration over the entire packing volume, $\mathrm{V}$ will result to the Merkel's equation, as:

$$
\frac{k^{`} a \mathrm{~V}}{\dot{\mathrm{m}}_{\mathrm{w}}}=\int_{t_{e}}^{t_{i}} \frac{c_{p w} d t_{w}}{H_{w}-H_{a}}
$$

where:

$$
H_{w}=C_{p} t_{w}+W_{w} h_{f g} \quad \text { and } \quad H_{a}=C_{p} t_{a}+W_{a} h_{f g}
$$

$H_{w}=$ the enthalpy of saturated air at the local water temperature, $\mathrm{kJ} / \mathrm{kg}$, $H_{a}=$ the enthalpy of air stream, $\mathrm{kJ} / \mathrm{kg}$, $k^{\prime}=$ mass transfer coefficient at the interface, $\mathrm{kg} / \mathrm{s} . \mathrm{m}^{2}$.

The term $\left(k \backslash a V / m_{w}\right)$ is frequently referred to as the CT characteristic. The meaning of this term is similar to that of NTU in heat exchanger design. Equation 12 has no closed-form solution. This is mainly because the enthalpy of saturated air does not vary linearly with the water temperature variation. On the other hand, to calculate the exit water temperature (for a given set of NTU condition and inlet condition of water and air), a trial and error method is required. A value of exit water temperature is assumed and the equations are solved iteratively.

\subsection{Cross flow CT}

A typical cross section of a cross flow $\mathrm{CT}$ is indicated schematically in Fig. 5. The water enters from the top and flows uniformly downward through the CT fill. The airflow is induced by a fan(s) and moves horizontally.

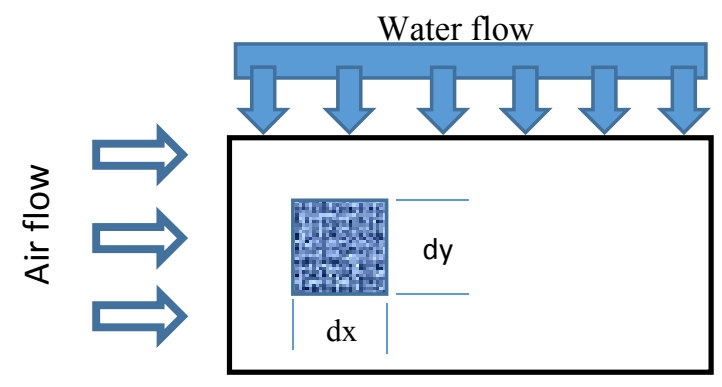

Figure 5: Elemental configuration in cross flow CT. 
Heat balance on the differential volume, dx.dy. $1 \mathrm{~m}^{3}$, as shown by Fig. 5, yields

$$
-G_{w} C_{p w}\left(d T_{w} / d y\right)=G_{a}\left(d H_{a} / d x\right)
$$

where, $G_{w}, G_{a}$ are the water and air flow rate per unit frontal area to flow direction (i.e. water and air loading, in $\mathrm{kg} / \mathrm{s} . \mathrm{m}^{2}$ ).

Applying thermal balance at the water-air interface, then

$$
-G_{w} C_{p w}\left(d T_{w} / d y\right)=k \backslash a\left(H_{w}-H_{a}\right)
$$

Combining eqn. 13 and eqn. 14, getting

$$
G_{a}\left(d H_{a} / d x\right)=k \backslash a\left(H_{w}-H_{a}\right)
$$

The driving force in the heat transfer process is the enthalpy difference $\left(H_{w^{-}}\right.$ $H_{a}$ ). Solution of the $\mathrm{CT}$ mathematical model requires two boundary conditions and property relationships.

\subsection{Fills of the CT}

The fill or packing, is the heart of the CT. It should provide both good water-air contact for high rates of heat and mass transfer and low resistance to air flow. It should also be strong, light, and deterioration-resistance. There are basically two types of fill: splash type and film, or so called non-splash type [6]. The CT fill performance is affected not only by the fill arrangement and type, but also by the water and air loading. Typical water and air loading for CT fills can be found in [2] and [3]. Low water loading results in poor water distribution, while a high water loading causes the CT to be flood, producing excessive air pressure losses. In both cases, these conditions cause a deteriorating fill performance. Another factor, to be considered in the selection of the CT fill, is the actual physical shape. The design calculations and selections of the fill for the present work is reported in details by [7].

\section{Results and discussion}

\subsection{Validity check of the design procedure}

The data of Al-Doarah 160 MW Power Station has been adopted to validate the developed design procedure. The solution was carried out under the assumption of $100 \%$ mixing ration, i.e. open cooling system. The developed mathematical model in the present work predicted the rejected heat as $230 \mathrm{MW}$; the temperature rise in the condenser is $12.2^{\circ} \mathrm{C}$, and the plant efficiency is $41 \%$. The results obtained are encouraging to use the developed procedure to predict the required CT design data. It is found that the efficiency of the plant is within the $41 \%$ range as stated by [4]. 
According to the documentation of Al-Dourah power Station, the starting efficiency of the plant is around 38-39\%.

The design data used in the present analysis are:

- Net output electrical power

- Loading ratio of the CT

- The cooling water temperature

- The maximum temperature

- The ambient conditions

$\begin{array}{ll}>\text { Dry-bulb temperature } & 40^{\circ} \mathrm{C} \\ >\text { Wet-bulb temperature } & 25^{\circ} \mathrm{C} \\ >\text { River water temperature } & 25^{\circ} \mathrm{C}\end{array}$

$200 \mathrm{MW}$

1.2

$23^{\circ} \mathrm{C}$

$32^{\circ} \mathrm{C}$

which are, the common design data in Iraq for air-conditioning and for thermal system.

\subsection{Analysis of the condenser results}

Fig. 6 illustrates the plant efficiency variation with the overall heat transfer coefficient inside the condenser at different flow rates. The prediction is based on 200 MW power plants. This figure helps to select suitable condenser tubes material, tubes diameter, and condensing surface area for a given plant efficiency and flow rate.

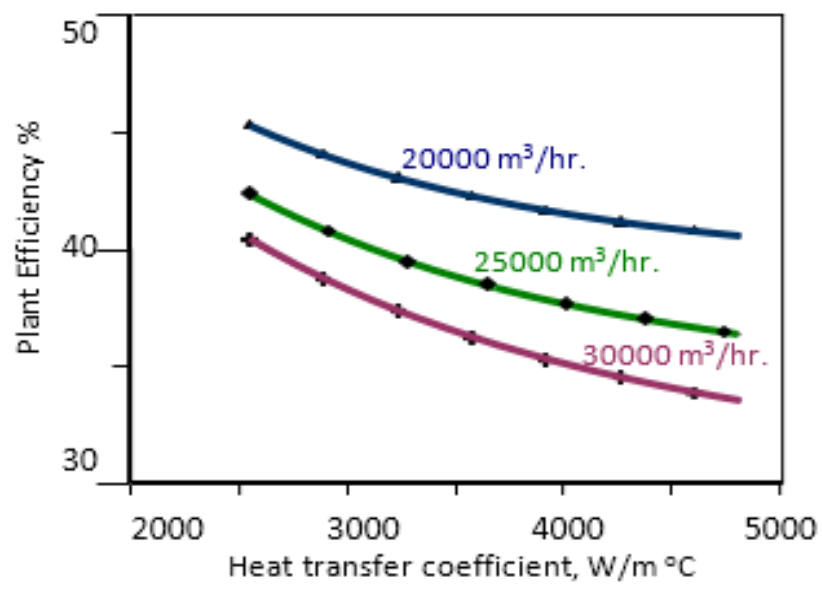

Figure 6: Predicted condenser efficiency at various flow rates of cooling water.

\subsection{Analysis of CT results}

Results of the CT size at various CMR is shown in table 1 for both types of CT. The prediction is carried out under the loading ratio of 1.2.

It is clear that the NTU is reduced considerably upon any CMR compared to the CCS. For both types, the cross flow and the counter flow, addition of $40 \%$ will 
reduce the amount of the NTU to the half. However, the designer has many choices to adopt. By selecting 0\% addition, the construction cost and the running cost should be accounted for since it requires larger size CT. In the selection of the plant site, the water resources are the first factor to be undertaken, therefore, possibility of at least $30 \%$ addition should be available. Recent results indicate an addition of CNR within range of 15 to $25 \%$ is highly advised.

Table 1: The cooling tower performance at different mixing ratios (1.2 loading ratio, $200 \mathrm{MW}$ power station).

\begin{tabular}{|c|c|c|c|c|c|}
\hline Mixing ratio & $0 \%$ & $10 \%$ & $20 \%$ & $30 \%$ & $40 \%$ \\
\hline $\begin{array}{c}\text { NTU, cross } \\
\text { flow }\end{array}$ & 1.5 & 1.31 & 1.12 & 0.9 & 0.71 \\
\cline { 1 - 4 } $\begin{array}{c}\text { NTU, counter } \\
\text { flow }\end{array}$ & 1.23 & 1.12 & 0.98 & 0.81 & 0.64 \\
\hline
\end{tabular}

Fig. 7 displays the prediction results of the outlet water temperature from the $\mathrm{CT}$ at various CMR, for both types of counter flow and cross flow CTs. The added water from the natural water resource is assumed at $25^{\circ} \mathrm{C}$. It is clear that as the CRM increases, the CT outlet temperature decreases considerably. When the CT operates at $\mathrm{CCS}$, i.e. $0 \% \mathrm{CMR}$, the outlet water temperature is $31.6^{\circ} \mathrm{C}$ for the cross flow $\mathrm{CT}$, and is $32.2^{\circ} \mathrm{C}$ for the counter flow CT. Results indicate that the CMR affect the values of the water outlet temperature in the cross flow CT more than in the case of the counter flow CT. Over range of CMR from $0 \%$ to $40 \%$, the outlet water temperature from the cross flow is $1{ }^{\circ} \mathrm{C}$ lower than the case of counter flow CT.

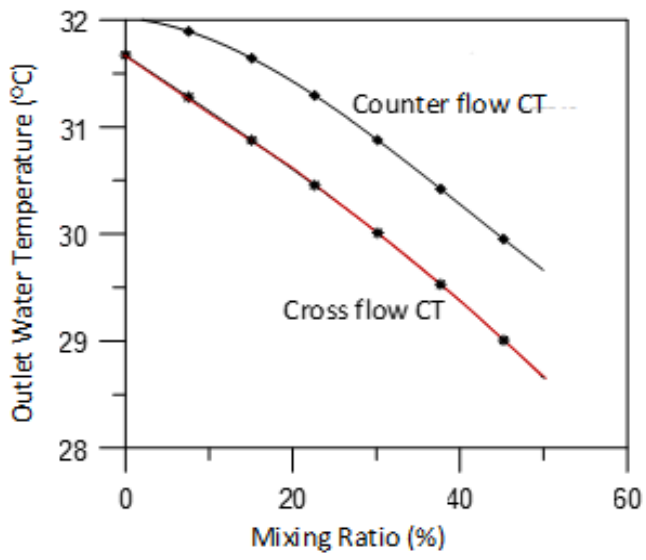

Figure 7: Predicted water outlet temperature from CTs at various CMR. 
The FD numerical results shown in Fig. 8 demonstrate that the height of the fill is not the significant dimension in the fill as the width of the fill may be more effective to achieve good performance of the fill package. The analyses in the present work are showing that the enthalpy rise per unit area facing the water flow direction is $58.4 \mathrm{~kJ} / \mathrm{kg}$ per unit area and in the area facing the air flow direction the enthalpy rise is $69.5 \mathrm{~kJ} / \mathrm{kg}$ per unit area. Although going towards width longer than the height is recommended, but there is a limit in the width up to the saturation air zone.

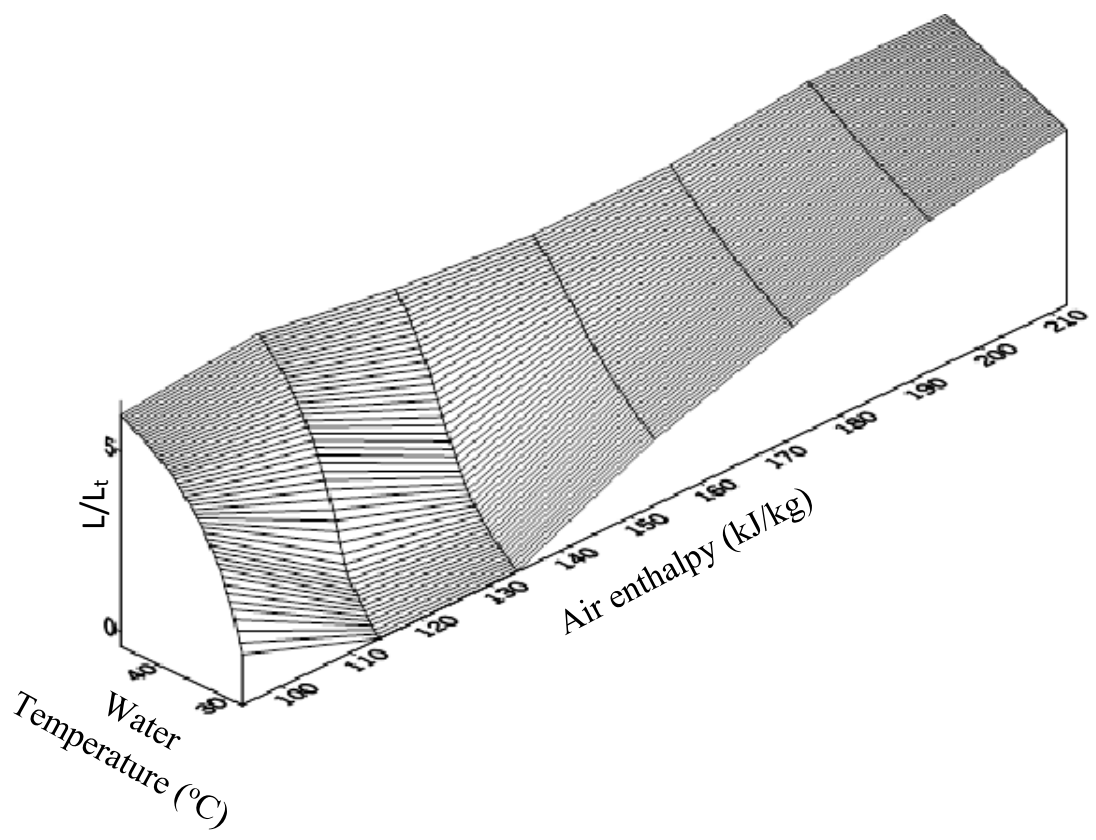

Figure 8: Finite difference numerical results showing the details of the water temperature and air enthalpy variation inside the fill package of cross flow CT.

\section{Conclusions}

Cooling system was suggested as alternative to the cooling water for $200 \mathrm{MW}$ thermal power plant, under Baghdad weather. Accordingly, design parameters of CT was achieved. A mathematical model was implemented based on the available literature and coded for computational solution. Also, a numerical model to solve study the heat/mass balance behavior in the fill package was carried out by Finite Difference technique. The work is mainly aim to design a CT. The results, in particular for the present paper, indicating that: 
- Using cooling mixing ratio of $15 \%$ to $25 \%$ is recommended for optimizing the size and cooling performance.

- Under similar operation and design conditions, the cross flow cooling tower produces cooled water with about $1^{\circ} \mathrm{C}$ less temperature than the counter flow cooling tower.

- The Finite Difference analyses of the cross flow cooling tower show that the hydrothermal performance is width (i.e. the air flow direction) is better than the that in the longitudinal (i.e. the water direction).

\section{Acknowledgements}

The authors acknowledge the Ministry of Electricity in Iraq for providing the financial under a contract base. Also, Universiti Teknologi PETRONAS is acknowledged for providing the technical and logistic support to produce the paper and also for the financial support to present the paper in ESUS2014.

\section{References}

[1] http://www.world-nuclear.org/info/Current-and-Future-Generation/CoolingPower-Plants/ (updated on July 2014, retrieved on Sept. 2014).

[2] El-Wakil, M. M., Power Plant Technology, McGraw-Hill, ISBN-13: 978$0072871029,2002$.

[3] Al-Kayiem, H.H. and Theeb, M. A. A., Alternative Solution for Cooling Water Shortage in Thermal Power Plants, $2^{\text {nd }}$ Int. Conf. Production, Energy and reliability, $2^{\text {nd }}$ ICPER, Kuala Lumpur Convention center, 2010.

[4] Li, W. K. and A. Priddey, A. P., Power Plants System Design, New York, Wiley, 1985.

[5] ASHRAE Hand book, HVAC System and Equipment, 1996.

[6] Fujita, T. and Tezuka, S, Calculations on Thermal Performance of Mechanical Draft Cooling Tower, ASHRAE Transaction, part 2-B, (1986).

[7] Al-Kayiem H.H. and Theeb, M. A. A., Cooling Tower Evaluation to Suit 200MW Thermal Power Plant, International Conference on Energy and Environment, $1^{\text {st }}$ ICEE, UNITEN, Malaysia, 2006. 